\title{
STEEL FABRIC REINFORCEMENT TO BS 4483
}

Made by welding steel wire into a rectangular mesh. Wire may be plain round, indented or otherwise deformed, welded or interwoven.

\begin{tabular}{|c|c|c|c|c|c|}
\hline \multirow[b]{2}{*}{ BS ref. } & \multicolumn{2}{|c|}{ Pitch } & \multicolumn{2}{|c|}{ Bar size } & \multirow[b]{2}{*}{ Description } \\
\hline & Main & Cross & Main & Cross & \\
\hline $\begin{array}{l}\text { A } 393 \\
\text { A } 252 \\
\text { A } 193 \\
\text { A } 142 \\
\text { A } 98\end{array}$ & 200 & 200 & $\begin{array}{r}10 \\
8 \\
7 \\
6 \\
5\end{array}$ & $\begin{array}{r}10 \\
8 \\
7 \\
6 \\
5\end{array}$ & Square mesh \\
\hline $\begin{array}{l}\text { B } 1131 \\
\text { B } 785 \\
\text { B } 503 \\
\text { B } 385 \\
\text { B } 283 \\
\text { B } 196\end{array}$ & 100 & 200 & $\begin{array}{r}12 \\
10 \\
8 \\
7 \\
6 \\
5\end{array}$ & $\begin{array}{l}8 \\
8 \\
8 \\
7 \\
7 \\
7\end{array}$ & Structural mesh \\
\hline $\begin{array}{l}\text { C } 785 \\
\text { C } 503 \\
\text { C } 385 \\
\text { C } 283\end{array}$ & 100 & 400 & $\begin{array}{r}10 \\
8 \\
7 \\
6\end{array}$ & $\begin{array}{l}6 \\
5 \\
5 \\
5\end{array}$ & Long mesh \\
\hline $\begin{array}{l}\text { D } 98 \\
\text { D } 49\end{array}$ & $\begin{array}{l}200 \\
100\end{array}$ & $\begin{array}{l}200 \\
100\end{array}$ & $\begin{array}{l}5 \\
2.5\end{array}$ & $\begin{array}{l}5 \\
2.5\end{array}$ & Wrapping fabric \\
\hline C 636 & $80-130$ & 400 & $8-10$ & 6 & Carriageway mesh \\
\hline
\end{tabular}

Note that BS reference is area of main steel per metre width.

Quality of steel: Hard drawn steel wire to BS 4461

Tensile strength $460 \mathrm{~N} / \mathrm{mm}^{2}$.

Standard sizes: Sheets $2.400 \times 4.800$

Rolls $2.400 \times 48.000$

Rolls $2.400 \times 72.000$.

Ordering procedure: BS 4483

Reference number

Type of material and process of manufacture

Number and size of sheets or rolls. 